\title{
O LABORATÓRIO DE ENSINO DE MATEMÁTICA NA FORMAÇÃO DE PROFESSORES: (RE) CONSTRUÇÕES DE SENTIDOS E PRÁTICAS EDUCATIVAS
}

\section{THE LABORATORY OF TEACHING OF MATHEMATICS IN TEACHER TRAINING: (RE) CONSTRUCTIONS OF SENSE AND EDUCATIONAL PRACTICES}

Carloney Alves de Oliveira ${ }^{1}$

\section{RESUMO}

Este artigo apresenta um relato de experiência de cunho exploratório sobre o uso do Laboratório de Ensino de Matemática (LEM) na formação de professores que ensinam Matemática no âmbito das atividades desenvolvidas na disciplina Saberes e Metodologia do Ensino da Matemática 1, turnos Vespertino e Noturno, no Curso de Pedagogia, na Universidade Federal de Alagoas (UFAL). O objetivo deste estudo foi refletir sobre a importância do LEM na formação de professores que ensinam Matemática como (re) construção de sentidos e práticas educativas, a partir da elaboração de atividades e oficinas temáticas desenvolvidas no mesmo. Em função das características do relato apresentado, bem como dos objetivos a serem alcançados, optou-se pelo desenvolvimento de um estudo descritivo, de natureza qualitativa. Os dados foram coletados mediante entrevistas semiestruturadas com os 36 alunos matriculados na disciplina, registros fotográficos e diário de campo. Constatamos que o uso do LEM pode proporcionar práticas pedagógicas capazes de dar conta das especificidades relacionadas ao ensino de Matemática como espaço para promoção do desenvolvimento da criatividade e do saber matemático.

PALAVRAS-CHAVE: Ensino de Matemática. LEM. Formação do pedagogo.

\section{ABSTRACT}

This article presents an exploratory experience report about the use of the Mathematics Teaching Laboratory (LEM) in the training of teachers who teach mathematics in the scope of the activities developed in the discipline Knowledge and Methodology of Teaching Mathematics 1, Evening and Night Shifts, in the Course of Pedagogy, at the Federal University of Alagoas (UFAL). The objective of this study was to reflect on the importance of LEM in the training of teachers who teach mathematics as (re) construction of meanings and educational practices, from the elaboration of thematic activities and workshops developed in it. Due to the characteristics of the report presented, as well as the objectives to be achieved, we chose to develop a descriptive study, of a qualitative nature. Data were collected through semi-structured interviews with 36 students enrolled in the discipline, photographic records and field diary. We found that the use of LEM can provide pedagogical practices capable of accounting for the specificities related to the teaching of mathematics as a space to promote the development of creativity and mathematical knowledge. KEYWORDS: Mathematics Teaching. LEM. Formation of the pedagogue.

\footnotetext{
${ }^{1}$ Professor Adjunto do Curso de Pedagogia na área de Saberes e Metodologias do Ensino da Matemática da Universidade Federal de Alagoas (UFAL). Pós-Doutor em Educação (UFS). Doutor em Educação (UFAL). Professor vinculado ao Programa de Pós-Graduação em Ensino de Ciências e Matemática (PPGECIM) da UFAL. Líder do Grupo de Estudos e Pesquisas em Tecnologias Educativas e Práticas Pedagógicas em Educação Matemática (GPTPEM). E-mail: carloneyalves@gmail.com
} 


\section{INTRODUÇÃO}

O Laboratório de Educação Matemática (LEM) tem sido o objeto de estudo de várias pesquisas em Educação Matemática de Lorenzato (2012), Rêgo; Rêgo (2012), Turrioni (2004), Passos (2012), Miskulin (2012) e Oliveira (1983). Nestas pesquisas, muito se tem discutido sobre as diferentes concepções de LEM, os objetivos, o papel e a importância deste laboratório na formação de professores, bem como as diferentes propostas de sua utilização nas diversas instituições de Ensino Superior comprometidas com a formação de professores.

O presente artigo se propõe a refletir sobre a importância do LEM na formação de professores que ensinam Matemática como (re) construção de sentidos e práticas educativas, a partir da elaboração de atividades e oficinas temáticas desenvolvidas no mesmo por meio de experimentação desenvolvida pelos alunos. O estudo foi desenvolvido numa turma com 38 alunos matriculados na disciplina de Saberes e Metodologias do Ensino da Matemática 1, durante o segundo semestre de 2018, no Curso de Pedagogia, do Centro de Educação (CEDU), da Universidade Federal de Alagoas (UFAL), nos turnos Vespertino e Noturno, apoiando nos princípios de um estudo empírico-exploratório de base qualitativa (MINAYO, 1994).

Partindo dessa realidade, estudiosos da área Lorenzato (2012), Passos (2012), Turrioni (2004) e Rêgo; Rêgo (2012) têm constatado, no universo acadêmico, as dificuldades de utilização do LEM na formação do pedagogo, decorrentes de um conhecimento ainda em estágio precário dos sujeitos envolvidos, tanto a respeito das características do LEM quanto das maneiras mais adequadas de empregá-las, resolvemos pesquisar sobre o LEM na formação do pedagogo, tendo como referencial a sua utilização no curso, buscando respostas para o seguinte questionamento: De que forma o LEM pode ser utilizado como possibilidade de prática pedagógica numa perspectiva dialógica, colaborativa e cooperativa para apropriação de conceitos matemáticos, pelos alunos de pedagogia?

O papel do LEM é contribuir para a melhoria da formação inicial e continuada de professores, promovendo a integração das atividades de ensino, pesquisa e extensão. Nesse sentido, segundo Rêgo; Rêgo (2012) o LEM possibilita estreitar as relações entre a instituição e a comunidade, atuando como parceira na solução dos problemas educacionais que esta apresenta, buscando a melhoria do ensino e constituindo um espaço de divulgação e de implantação de uma cultura de base científica.

Com o LEM é possível também estimular a prática da pesquisa em sala de aula, baseada em uma sólida formação teórica e prática; e firmar projetos de parceria com os sistemas locais de ensino, visando à instalação de clubes e laboratórios de Matemática, além de oficinas e cursos de formação continuada para seus professores.

O ambiente deste laboratório proposto deve funcionar, segundo Turrioni (2004), como [...] "um centro para discussão e desenvolvimento de novos conhecimentos dentro de um curso de licenciatura em Matemática, contribuindo tanto para o desenvolvimento profissional dos futuros professores como para sua iniciação em atividades de pesquisa".

Seguindo essas características, portanto, este laboratório passa a ser entendido como um agente de mudança num ambiente onde se encontram esforços de pesquisa na busca de novas alternativas para o aperfeiçoamento do curso de Pedagogia, bem como do currículo da Educação Infantil e Ensino Fundamental I, já que estes profissionais atuarão nesse campo.

O LEM deverá favorecer, durante a formação inicial, a integração das disciplinas de formação pedagógica com as disciplinas de formação profissional, promovendo articulação da teoria com a prática. Deverá, ainda, preparar professores com uma formação mais próxima das pesquisas recentes e imbuídos de um sentimento de indagação e procura (BICUDO; BORBA, 2005).

Enfim, somos desafiados a cada dia no contexto educacional a entender que, com o LEM se deve ao fato de que é possível subsidiar os professores com propostas pedagógicas envolvendo a utilização de metodologias alternativas para o ensino da Matemática, como também orientar a construção e utilização de material didático manipulável e de tecnologias digitais nos processos de ensino e de aprendizagem da Matemática.

É possível com o LEM proporcionar o desenvolvimento da criatividade, da agilidade e da capacidade de organização do pensamento e comunicação de nossos alunos, buscando estimular e capacitá-los para atuarem como investigadores e pesquisadores no 
ambiente da sala de aula e possibilitar estratégias para manter uma visão crítica construtivista da sociedade e do currículo.

Visando contextualizar melhor as razões pelas quais o LEM pode ter um lugar acentuado na formação inicial de professores que ensinam Matemática, organizamos o artigo em três seções: na próxima seção discutimos aspectos relativos ao LEM e a formação do pedagogo, suas concepções, desafios e possibilidades em contextos de ensino e de aprendizagem; a seguir enfatizamos as questões metodológicas referentes ao relato de experiência desenvolvido que deu origem a esse artigo; e na sequência realizamos a apresentação das etapas com os dados obtidos, e por fim algumas considerações acerca da experiência relatada.

\section{O LEM NA FORMAÇÃO DO PEDAGOGO: DESAFIOS E POSSIBILIDADES}

O desenvolvimento e a utilização do LEM, no cenário da formação do pedagogo para o ensino e a aprendizagem matemática como processo educativo, podem possibilitar uma criação dialógica entre professor e aluno pelas interações com seus materiais concretos e mídias, auxiliando tais sujeitos a desempenharem seu papel em sala de aula e na construção do conhecimento matemático de maneira rápida e precisa (OLIVEIRA, 1983).

O espaço físico para a realização das atividades deste laboratório, portanto, é definido como:

uma sala-ambiente para estruturar, organizar, planejar e fazer acontecer o pensar matemático, é um espaço para facilitar, tanto ao aluno como ao professor, questionar, conjecturar, procurar, experimentar, analisar e concluir, enfim, aprender e principalmente aprender a aprender (LORENZATO, 2012, p. 7).

Assim, esse é um ambiente que propicia, "[...] às crianças, aos futuros professores e aos professores formadores um conjunto de explorações e investigações matemáticas com o propósito de descobrir alguns princípios matemáticos, padrões e regularidades" (PASSOS, 2012, p. 90).

Dessa forma, a construção desse conhecimento se dá de forma dialética, por meio de uma ação reflexi- va, havendo sempre a mediação do professor entre o objeto a ser conhecido e o sujeito (aluno).

Durante o desenvolvimento desse processo, cabe ao professor, então, oportunizar aos alunos momentos de reflexão durante a interação destes com o objeto a ser conhecido, de forma que experiências individuais de formação e transformação possam surgir de forma significativa para cada um que esteja envolvido nesse processo (ALVES, 2001).

Nesse contexto, os materiais didáticos "criam vida" à medida que dinamizam e enriquecem as atividades de ensino-aprendizagem. Sendo assim, é recomendável que estes materiais sejam utilizados como um meio auxiliar na construção do conhecimento matemático e não como um objeto material com finalidade em si mesmo (OLIVEIRA, 1983).

A proposta de pesquisa com o LEM para a formação do pedagogo aqui apresentada, reflete na ideia de que neste ambiente é possível proporcionar ao aluno maior autonomia de pensamento, de modo que este seja capaz de observar, refletir e questionar por si mesmo situações, possibilitando um contato mais próximo do mesmo com a Matemática, aumentando, assim, a sua perseverança na busca de soluções e a confiança na sua capacidade de aprender e investigar (FIORENTINI; LORENZATO, 2006).

O LEM pode ser utilizado como um catalisador de uma mudança no paradigma educacional, que promova a aprendizagem ao invés do ensino, que coloquem o controle do processo de aprendizagem nas mãos do aprendiz. Isso auxilia o professor a entender que a educação não é somente a transferência da informação, mas um processo de construção do conhecimento do aluno, como produto do seu próprio engajamento intelectual ou do aluno como um todo.

Segundo Passos (2012, p. 90) o LEM pode ser entendido,

como um ambiente onde ocorre um processo; constitui-se em cenário que permite que projetos individuais possam ser investigados por diferentes atores. [...] o LEM não pode ficar restrito a lugar ou processo, devendo incluir atitude. [...] é levar os estudantes a pensar por eles mesmos, a questionar, observar padrões, desenvolver uma atitude de investigação.

Uma outra concepção sobre o LEM, segundo 
Lorenzato (2012, p. 7), é que este

em condições desfavoráveis, pode tornar o trabalho altamente gratificante para o professor e a aprendizagem compreensiva e agradável para o aluno, se o professor possuir conhecimento, crença e engenhosidade. Conhecimento porque, tendo em vista que ninguém ensina o que não sabe, é preciso conhecer Matemática, mas também metodologia de ensino e psicologia, enfim, possuir uma boa formação matemática e pedagógica; crença porque, como tudo na vida, é preciso acreditar naquilo que se deseja fazer; e engenhosidade porque, muito frequentemente, é exigida do professor uma boa dose de criatividade, como também para orientar seus alunos e transformá-los em aprendizes.

Corroborando com os autores anteriores, podemos afirmar que o potencial pedagógico do LEM na formação do pedagogo pode permitir e oferecer aos seus usuários acesso à informação, conversação com os sujeitos envolvidos e a liberdade de navegabilidade em tempo e espaço.

Da mesma forma pode possibilitar, de forma integrada, no desenvolvimento de tarefas, veiculação de dados, ajustes às necessidades e aos objetivos de cada curso, na organização, reorganização e flexibilização curricular, a fim de atender às novas exigências para a construção do conhecimento sistematizado, que instiguem à investigação e à curiosidade do sujeito em formação (MISKULIN, 2012).

Seja qual for a abordagem para o uso do LEM na formação do pedagogo, é preciso que o professor, ao realizar atividades educativas, elabore o seu planejamento a partir de estratégias didáticas e mecanismos de avaliação para atender aos objetivos e necessidades do grupo que sustentem um espaço que vai se desdobrando para uma diversidade de caminhos que não estabeleçam limites para a imaginação.

Com a utilização do LEM no contexto educacional, professores e alunos precisam ser muito flexíveis e criativos na valorização da construção coletiva, da criatividade, da aprendizagem através dos materiais didáticos manipuláveis, das trocas, da constante interação, privilegiando, além do cognitivo, o afetivo e o intuitivo, para potencializar estratégias didáticas que estabele- çam relações que possam contribuir para a constituição de um conhecimento coletivo, levando o sujeito a atitudes de criação e autoria, acompanhando cognitivamente o processo de aprendizagem objetivado.

No entanto, é preciso criar condições para que alunos e professores venham a utilizar o LEM não somente em sala de aula, mas no seu cotidiano, pois, conforme Miskulin (2012) é preciso conceber um laboratório como um cenário interativo de aprendizagem colaborativa, compreender o entorno e atuar nele.

Com este ambiente do LEM é possível ser um receptor crítico dos meios de comunicação, localizar a informação e utilizá-la criativamente e locomover-se bem em grupos de trabalho e produção de saber, no qual os futuros professores e professores em exercício possam refletir conjuntamente sobre as suas práticas.

Enfim, no LEM podemos compartilhar propostas pedagógicas, exercitando no dia a dia tarefas que permitam superar dificuldades e limitações do seu uso em sala de aula, além de possibilitar momentos de comunicação e expressão.

\section{DELINEANDO A PESQUISA: O CAMINHO METODOLÓGICO}

A pesquisa foi desenvolvida no âmbito do grupo de pesquisa em Educação Matemática do Estado de Alagoas e compreendida como um processo criativo, sendo um estudo, de cunho exploratório, que ofereceu informações do contexto local e do objeto focalizado, quer em termos de objeto - O LEM por meio de atividades práticas na formação do pedagogo - quer em termos espaciais - 38 alunos matriculados (Vespertino e Noturno), na turma de Saberes e Metodologias do Ensino da Matemática 1, no Curso de Pedagogia - CEDU/UFAL, durante o segundo semestre de 2018.

Partindo desta compreensão, optamos pela pesquisa colaborativa, numa abordagem qualitativa, por entender, segundo Flick (2004), que a pesquisa ocorre em um cenário natural, a partir das expressões e atividades das pessoas em seus contextos locais, buscando conhecer o que é dito, quem são os sujeitos que falam, considerando este como o cenário social por meio de análises de uma amostra, buscando a validade da pesquisa.

As técnicas e os instrumentos de pesquisa adequados às especificidades do fenômeno estudado fo- 
ram: observação participante nas atividades propostas nas oficinas organizadas no LEM, envolvendo a parte descritiva e reflexiva do campo de pesquisa, dentre elas a descrição do sujeito, reconstrução dos diálogos e descrição das atividades realizadas pelos alunos a fim de construir conhecimento a respeito do problema investigado e entrevistas semiestruturadas.

O estudo foi desenvolvido durante o segundo semestre do ano de 2018 nas seguintes etapas:

$1^{\text {a }}$ etapa: Os alunos foram organizados em pequenos grupos, para compreenderem a dinâmica e reconhecimento dos materiais didáticos manipuláveis disponíveis no LEM.

$2^{a}$ etapa: Apresentação e análise destes materiais, buscando fazer relação com o ensino de Matemática, seus objetivos e como poderiam ser utilizados em sala de aula.

$3^{\text {a }}$ etapa: Elaboração e desenvolvimento de situações problemas para o aprendizado dos conceitos matemáticos levantados durante a etapa de análise dos materiais.

$4^{a}$ etapa: Socialização das atividades elaboradas pelos alunos e diálogos sobre as possíveis soluções e aplicações com o intuito de perceber a reação dos alunos participantes ao interagirem com o material didático manipulativo, assim como a construção dos conhecimentos pretendidos.

$5^{a}$ etapa: Ao final do segundo semestre do ano de 2018 após conclusão das atividades planejadas para o uso do LEM durante as aulas, os alunos foram entrevistados a partir das seguintes questões:

- Já participou de algum curso que envolvesse o LEM? Se positivo, qual?

- O que sabe sobre o LEM?

- O LEM é um ambiente de fácil navegabilidade? Por quê?

- Quais as maiores dificuldades encontradas ao participar deste curso através do LEM?

- Com as atividades propostas e realizadas no LEM curso sentiu dificuldade de manuseio dos materiais disponibilizados e elaborados? Quais? Por quê? O que chamou atenção em cada uma delas?

Por fim, o caminhar metodológico da pesquisa é flexível, compreendendo que ao lado da coleta de dados outros elementos foram dando vida à interpreta- ção das informações, bem como outros procedimentos potencializaram a análise dos dados, a fim de garantir o resguardo dos objetivos pretendidos pela pesquisa, buscando potencializar os processos de ensino e de aprendizagem nas aulas de Matemática a partir de atividades que propiciaram interações e estímulos na construção do conhecimento matemático na formação do pedagogo no LEM.

\section{POSSIBILIDADES E IMPLICAÇÕES DO LEM NA FORMAÇÃO DO PEDAGOGO}

Entendendo que a familiaridade dos alunos com o conhecimento matemático se origina nos primeiros momentos escolares e que as situações que os levam a aprendizagem da disciplina perpassam a metodologia que foi empregada (LORENZATO, 2012), percebe-se que o problema não está na Matemática como conhecimento e sim nas práticas pedagógicas no processo de ensino e aprendizagem desse saber.

A partir das observações ao longo das atividades realizadas no LEM e, em seguida, mediante algumas entrevistas com os alunos, constatamos que já ouviram falar em LEM, sabem o básico sobre este espaço e que nunca o utilizaram.

Quando foram questionados na entrevista sobre a sua compreensão do LEM e sua utilização nas aulas de Matemática, alguns sujeitos relataram que o LEM é um ambiente "agradável e que é possível utilizá-lo para que as aulas se tornem mais prazerosas e curiosas, pudendo acompanhar a disciplina de forma tranquila. (A1)", "uma ferramenta boa e que tem bons momentos de interação entre nossos colegas e que podemos usufruir o máximo que for possível das explicações. (A12)", "no LEM, dependendo do conhecimento que se tenha do conteúdo proposto, é possível entender e interagir com o professor no momento de discussão do assunto trabalhado na sala de aula com as atividades propostas. (A36)" e "posso dizer que é a ludicidade nos espaços de formação é um ambiente rico e com uma fonte aberta de conhecimentos voltada para a educação. (A15)".

A partir dessas respostas podemos confrontar com o que afirma Lorenzato (2012) sobre o LEM, quando salientam que este ambiente, é um espaço propício para estimular no aluno o gosto pela matemática, a 
perseverança na busca de soluções e a confiança em sua capacidade de aprender e fazer matemática.

Ao longo do semestre (2018.2) foram trabalhados diversos conteúdos, tais como: Sistema de Numeração Decimal, Quatros operações, Frações, Geometria e Sistema Monetário Brasileiro, e os alunos foram convidados a participar e refletir sobre cada oficina temática que seria trabalhada no LEM e a importância de cada uma delas para a sua formação, apontando aspectos relevantes que pudessem contribuir na sua prática em sala de aula.

É necessário que as oficinas matemáticas sejam modeladas em função do público alvo de cada aula de Matemática, remetendo os alunos à sua própria experiência e vivência dos ambientes de ensino que promovam a socialização do conhecimento e a integração do grupo nas atividades propostas. São muitas as funcionalidades oferecidas pelas oficinas e muitas são as possibilidades de modelagem desse ambiente para as aulas de Matemática.

Uma vez evidenciado que foi possível trabalhar com atividades que enviam alguns conteúdos matemáticos como de construção de figuras planas e espaciais, no LEM, por exemplo, procuramos articular a teoria e a prática a partir das múltiplas formas de simulações (PASSOS, 2012) que possam despertar a curiosidade (fig. 1).

Figura 1: Material didático manipulativo sobre Geometria Plana e Espacial

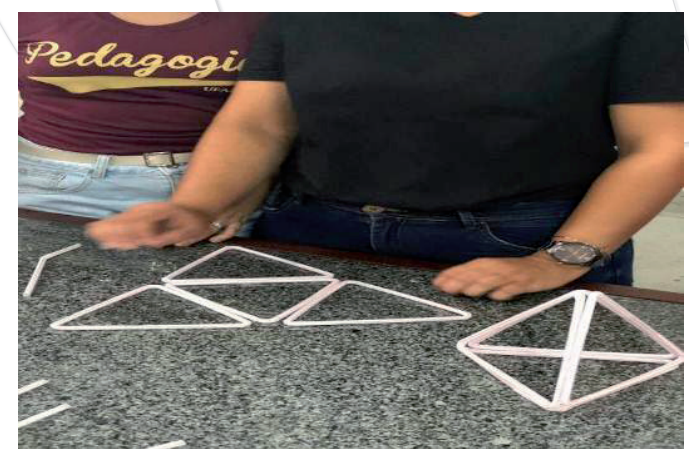

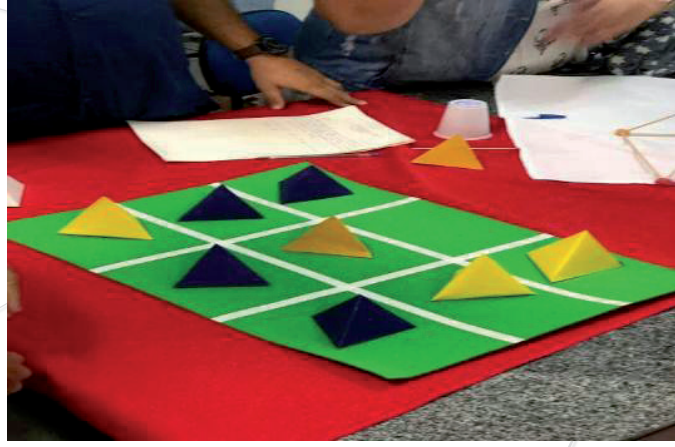
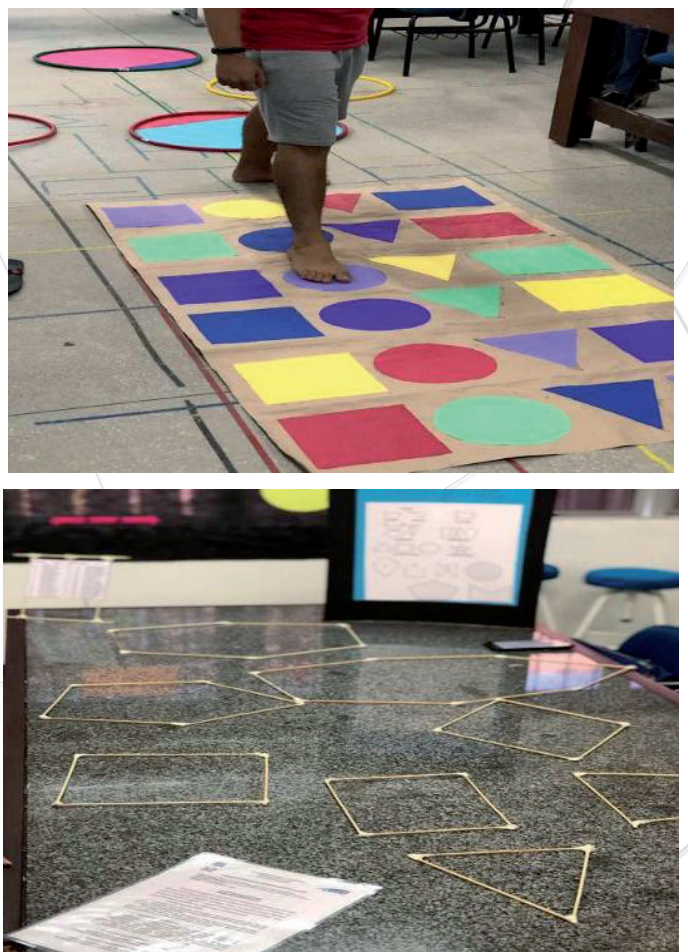

Fonte: Arquivo pessoal do autor (2018)

Nestas atividades buscamos impulsionar o aluno a lidar com materiais concretos, e proporcionando interatividade e o compartilhamento da informação entre os sujeitos envolvidos, buscando diferenciar as figuras planas das espaciais, reconhecer polígonos, poliedros e corpos redondos, desenvolvendo habilidades de observação, principalmente do espaço de três dimensões, para conseguir representá-lo, interagir com ele e até mesmo transformá-lo, ainda que apenas abstratamente.

Constatamos que é preciso se utilizar de uma linguagem clara e objetiva para a elaboração das atividades propostas no LEM, estando atento a algumas situações, como as mencionadas, incorporando o papel de professor, interagindo efetivamente ao longo do 
curso, pois, é preciso manter uma troca constante de informações, em que todos os envolvidos sejam agentes e o diálogo seja a base das negociações.

Ao longo do curso, os alunos foram capazes de avaliar suas estratégias e formas de trabalhar com o LEM, mesmo sendo mínima inicialmente a sua participação. À proporção que se reflete sobre a postura e a prática de cada aluno no curso, o aluno A20 em entrevista percebe-se o aperfeiçoamento da utilização dos materiais didáticos manipulativos e a compreensão da dinâmica de utilização da proposta pedagógica de cada atividade apresentada:

O avanço que tive ao longo do curso, minha autonomia, utilização dos materiais e compreensão da proposta pedagógica de cada um deles, sendo mais maduro para compreender toda a dinâmica de usabilidade dos mesmos, percebi o grande fascínio e estímulo deste espaço para a nossa formação. A cada encontro uma expectativa de como seria e o que faríamos durante o curso. (A20)

A formação do pedagogo em relação a utilização dos materiais disponíveis no LEM, permitiu que o sujeito em formação resgatasse a vontade aprender e conhecer mais a Matemática, buscando procedimentos de orientações de atividades e de construção de um ambiente de ensino e de aprendizagem interativo e colaborativo nos espaços de formação do professor, bem como o acompanhamento, exploração dos recursos disponíveis e comunicação entre os sujeitos envolvidos (Fig. 2).

Figura 2: Interação dos alunos com o material didático manipulativo

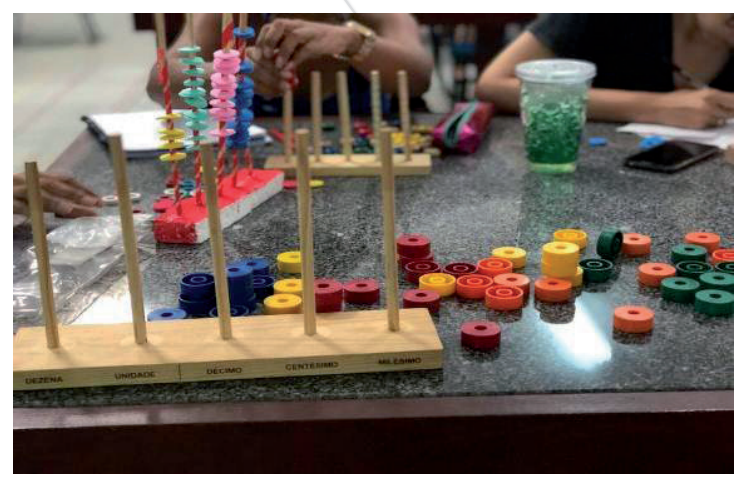

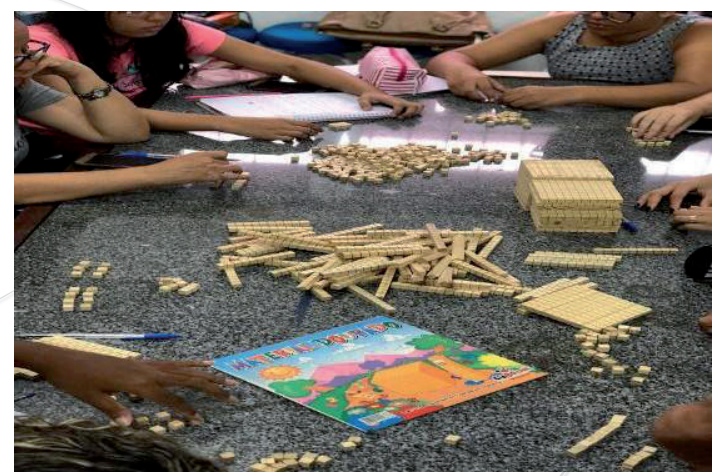

Fonte: Arquivo pessoal do autor (2018)

Ao possibilitar interações, os alunos A1, A20 e A7 assumiram o seu papel ativo: conduzir tal situação, na tentativa de refletir diante de situações-problema em cursos nesse formato dentro de um LEM, facilitando a assiduidade do aluno ao curso e a condução devida para realização das atividades, em que se buscaram contribuições para a discussão, desenvolvimento e reconhecimento de alternativas do contexto educacional, como revelam as falas desses sujeitos da pesquisa após entrevista realizada, buscando informações se o LEM foi um ambiente favorável para a realização de atividades práticas que articulassem com a teoria estudada:

Gostei do ambiente e das atividades propostas nele, consigo expor os pontos positivos e negativos, com comentários da realidade vivida, em relação alguns momentos de ausência dos colegas e a falta de leitura dos materiais expostos. Vou apenas reforçar a questão das aulas práticas; mesmo com dificuldade para me adaptar a tal realidade, o professor buscou alternativas viáveis. Aos poucos você irá perceber que existem alternativas simples para preparar aulas práticas, de forma suficiente para marcar suas aulas. (A1)

Muito importante esse curso, pois precisamos de uma formação inicial e continuada através desses ambientes para que possamos refletir sobre a nossa prática pedagógica. (A20)

Precisamos formar mais pedagogos que ensinarão Matemática com essa visão de uso do LEM, pois nas nossas escolas, existem muitos espaços que poderiam ser utilizados como o LEM para que os nossos alunos possam utilizá-los, e 
a aprendizagem pode sim, com certeza, se através do LEM e de seus materiais disponíveis ou elaborados pelos próprios alunos. (A7)

Na busca da organização das ideias a respeito de cada atividade apresentada no LEM, na realização dos desafios propostos, os alunos A9 e A15 quando questionados na entrevista sobre o que é o LEM como espaço de criação para situações pedagógicas, afirmaram que tiveram dificuldades para compreender a importância do LEM na sua formação, mas que buscarão fazer uso dos materiais disponíveis, permitindo um trabalho autônomo de cada sujeito, observando os conhecimentos prévios quanto à utilização destes recursos e as possíveis intervenções, conforme relatos abaixo:

Preciso melhorar a minha visão do LEM ao longo do curso. Por agora, só vou enfatizar a questão da minha participação, mais uma aprendizagem sem igual, e acredito que irei melhorar mais e mais, pois ter uma certa regularidade faz a diferença. (A9)

Inicialmente tive uma grande dificuldade para relacionar a teoria com a prática nestes espaços, mas, como a formação do professor começa mesmo antes do início de sua escolarização, e se dá na forma de processo, podemos destacar o período que vivenciamos no LEM como momento de grande importância para a formação docente. (A15)

A formação do pedagogo com o apoio do LEM é um caminho essencial a trilhar, capacitando os professores a refletir e utilizar o saber compreendido nessa formação (OLIVEIRA, 1983), bem como à lógica do seu uso no campo político-pedagógico ao inquirir a forma que se deve utilizar.

As contribuições de cada sujeito envolvido fizeram emergir uma participação ativa e colaborativa que suscitou dos alunos também em atividades envolvendo as tecnologias móveis (celular e tablets) (fig. 3), na trajetória durante o curso, uma reflexão sobre a formação do professor nesses ambientes, permitindo sustentar que é possível ensinar e aprender Matemática por meio do LEM, desde que se articule a teoria e a prática para suas intervenções.
Figura 3: Participação dos alunos com tecnologias móveis
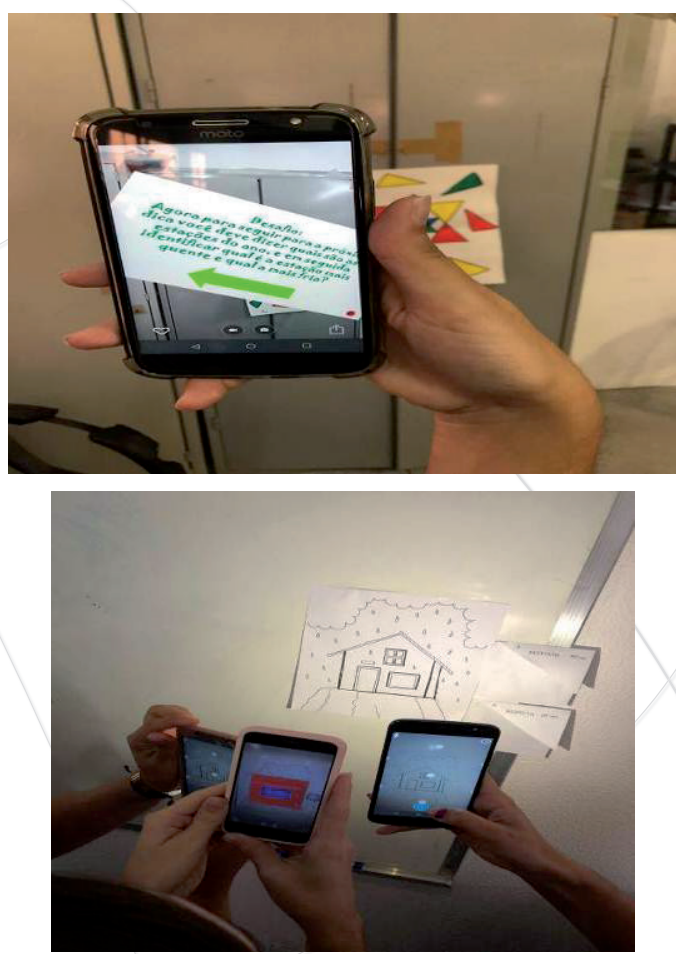

Fonte: Arquivo pessoal do autor (2018)

Para Passos (2012), a parceria entre professor e alunos no LEM permite a troca de ideias e informações, recuperando o sentido da responsabilidade, da contribuição e compromisso de tecer redes interativas e cooperativas que possibilitaram intervenções do conteúdo veiculado no ritmo de cada sujeito envolvido na atividade.

Com o LEM podemos fazer uso desse conhecimento voltado para a contextualização como aporte pedagógico, sem uma caracterização ou uma indicação mais social ao seu uso, ou até mesmo não o utilizando, mas descartando-o completamente, fazendo uma opção pelo modo tradicional do seu uso pedagógico.

Podemos estimular a sinergia das competências na elaboração também de materiais concretos (fig. 4), o que poderá ser um caminho na identificação de novos questionamentos que permitirão reformas ou reestruturações futuras nos cursos de formação de professores, abrindo espaço para dimensões coletivas e cooperativas, já que é possível formar o professor em ambientes de aprendizagens diferentes (participativo, interativo, criativo, aberto, contextualizado, humano, justo). 
Figura 4: Elaboração de materiais concretos
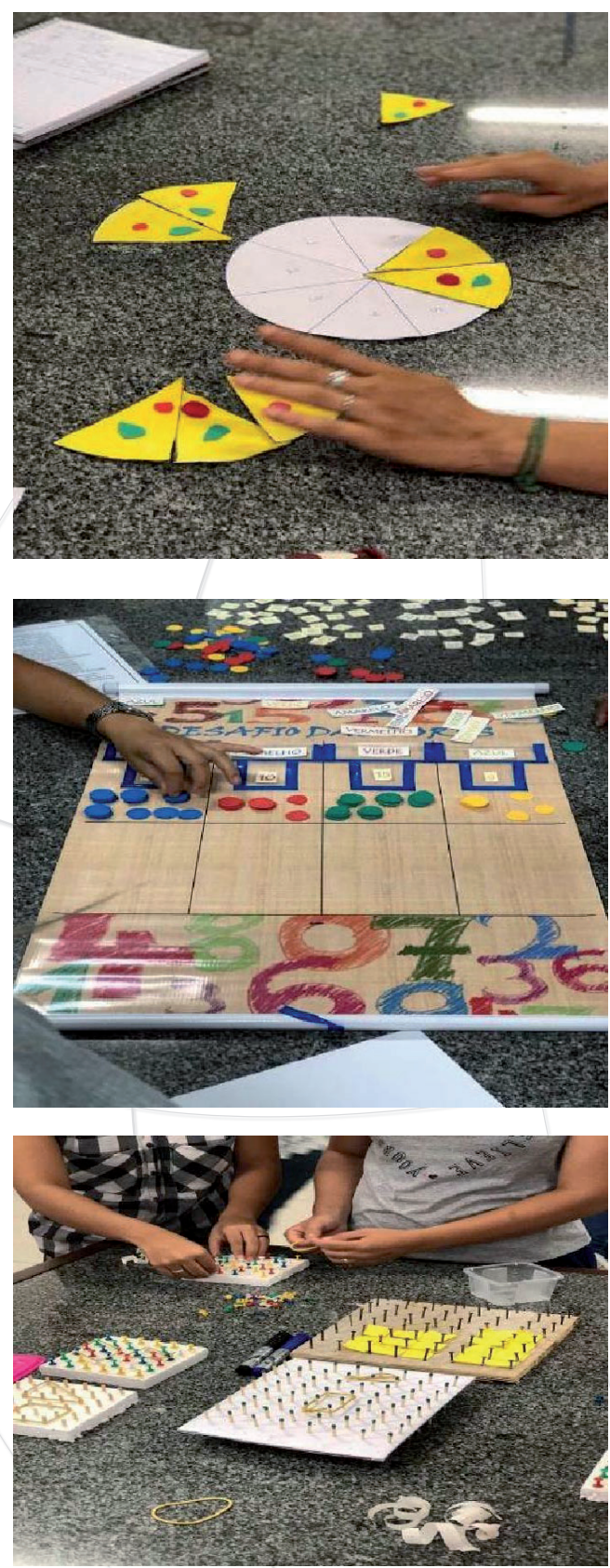

Fonte: Arquivo pessoal do autor (2018)

Nesse âmbito, é necessário pensar numa concepção de formação que compreenda um conjunto possível de formas de interação e de cooperação entre pesquisadores, formadores, professores e outros atores do espaço acadêmico suscetíveis de favorecer a prática reflexiva e a profissionalização interativa a partir do LEM.

De fato, as contribuições dos alunos apontaram para o sucesso no decorrer do curso, uma vez assumida a responsabilidade e a curiosidade do aprender a usar os materiais didáticos manipulativos disponibilizados no LEM e as estratégias apresentadas para a resolução dos problemas com mais propriedade e interesse, não se limitando apenas a respostas curtas, sem os devidos encaminhamentos para conduzir os sujeitos à autonomia, à liberdade e à reflexão crítica no processo interativo.

Percebemos que é possível integrar materiais didáticos manipulativos para a formação de cada sujeito, quando afirma Lorenzato (2012) que o LEM pode ser um espaço de aprendizagens matemáticas, e que requer por parte do professor uma melhor percepção do processo educacional nestes ambientes e uma melhor identificação dos atores e seus papéis no desenvolvimento da prática educativa, baseada num conjunto de conteúdos curriculares a partir de estudos, pesquisas, atividades acadêmicas e extracurriculares.

Formar professores mediante tal perspectiva requer uma preocupação com esses profissionais para que sejam capazes de trabalhar em suas áreas específicas do conhecimento através de situações-problema que impulsionem a construção do conhecimento, buscando suporte em concepções pedagógicas baseadas na pesquisa, no acesso à informação, na complexidade, na diversidade e na imprevisibilidade, de modo a favorecer estratégias didáticas com utilização do LEM.

A formação do pedagogo com o apoio do LEM surge como uma possibilidade de superação das necessidades, carências e desafios atuais da educação (TURRIONI, 2004), pois se deve promover o desenvolvimento de educadores críticos, autônomos, criativos, que solucionem problemas em contextos imprevistos, que questionem e transformem sua própria sociedade, em suma, que sejam sujeitos de seu próprio ambiente.

Os novos cenários requerem desenvolver nos pedagogos em formação, a habilidade e a competência para o uso do LEM, a agilidade de raciocínio mental e formal, autonomia e criatividade, para que os grandes desafios sejam superados nos processos formativos em sua docência. Considerar a importância dessa formação para a docência é superar limites no aprender a ser professor, que não é tarefa fácil, mas sempre um aprendizado por meio de situações teóricas e práticas, com uma bagagem sólida no âmbito científico, atuando reflexivamente com flexibilidade e responsabilidade no trabalho docente. 


\section{CONSIDERAÇÕES FINAIS}

As práticas pedagógicas segundo Lorenzato (2012) com a utilização do LEM na formação do pedagogo, podem ser aplicadas para trabalhar assuntos das mais diversas áreas da Matemática, desde o ensino de aritmética, álgebra até o ensino de Geometria, de tal forma que as estratégias escolhidas pelo professor possam conduzir as atividades planejadas nestes ambientes de forma lúdica, dinâmica e criativa, deixando de lado, a prática mais frequente nas aulas de Matemática, em que o professor apresenta o conteúdo oralmente, partindo de definições, exemplos, demonstrações de propriedades, seguidos de exercícios de aprendizagem, fixação e aplicação, e pressupondo que o aluno aprende pela reprodução.

Identificou-se que a formação poderá ser beneficiada através de inúmeras atividades que se permitem fazer no ambiente, como a aprendizagem de conceitos matemáticos através de materiais didáticos manipulativos, as discussões que envolvem metodologias de ensino, os momentos desafiadores na produção de recursos didáticos, oficinas temáticas e sequências didáticas que levam ao graduando a momentos de pesquisas e leituras.

Por outro lado, nas ações formativas que envolvem a manipulação (PASSOS, 2012) e o reconhecimento das tecnologias pode ser possível utilizá-las no processo de ensino-aprendizagem nas aulas de Matemática para possibilitar uma reflexão sobre a prática, o desenvolvimento da autonomia, e principalmente da familiarização com o conhecimento matemático.

Entendemos que a formação do pedagogo no contexto do LEM como apoio ao processo de ensino e aprendizagem representa um avanço nas formas de interação entre professor e aluno, bem como na variedade de recursos que podem ser utilizados em sala de aula. Evidentemente, a presença dos recursos lúdicos é indispensável, mas desde que os mesmos possam ser entendidos e explorados com ênfase na criatividade e na metamorfose (mudança, transformação de si e do contexto local).

Enfim, é possível sensibilizar e fazer com que os pedagogos que ensinarão Matemática acompanhem esse processo tão dinâmico, com uma linguagem acessível e que proporcione a interatividade de todos os envolvidos. Torna-se necessário, dentro do universo do LEM, imergir e desenvolver ambientes colaborativos e criativos em contextos educacionais, incorporando materiais didáticos manipulativos que atribuam significado para a aprendizagem, e possibilitem a criação de situações para que o aluno redescubra padrões, regras e relações, promovendo o sucesso e evitando o "fracasso".

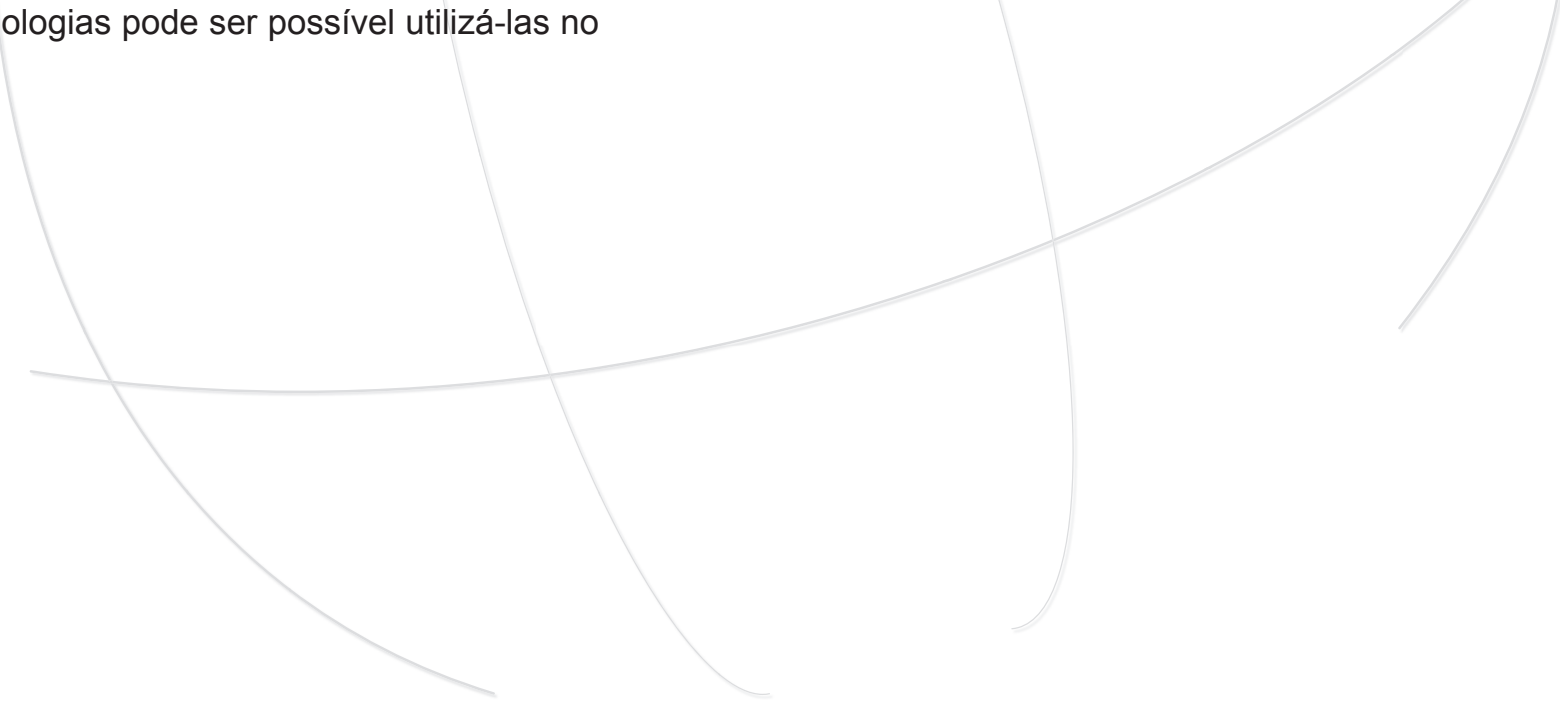




\section{REFERÊNCIAS}

ALVES, E. M. S. A Ludicidade e o ensino de matemática: uma prática possível. Campinas: Papirus, 2001.

BICUDO, M. A. V.; BORBA, M. de C. (Orgs.). Educação matemática: pesquisa em movimento. 2 . ed. São Paulo: Cortez, 2005.

FIORENTINI, D.; LORENZATO, S. Investigação em educação matemática: percursos teóricos e metodológicos. Campinas: Editores Associados, 2006.

FLICK, U. Uma introdução à pesquisa qualitativa. 2. ed. Porto Alegre: Bookman, 2004.

LORENZATO, S. (Org.). O laboratório de ensino de matemática na formação de professores. Campinas: Editores Associados, 2012.

MINAYO, M. C. de S. O desafio do conhecimento: pesquisa qualitativa em saúde. São Paulo: Hucitec, 1994.

MISKULIN, R. G. S. As potencialidades didático-pedagógicas de um laboratório em educação matemática mediado pelas TICs na formação de professores. In: LORENZATO, Sérgio. Laboratório de ensino de matemática na formação de professores. Campinas: Autores Associados, 2012. p. 153-178.
OLIVEIRA, A. M. N. Laboratório de ensino e aprendizagem em matemática: as razões de sua necessidade. Dissertação (Pós-graduação em Educação) - Universidade Federal do Paraná, Curitiba, PR. Orientador: Lauro da Silva Becker. 1983, 138 p.

PASSOS, C. L. B. Materiais manipuláveis como recursos didáticos na formação de professores de matemática. In: LORENZATO, Sérgio. Laboratório de ensino de matemática na formação de professores. Campinas: Autores Associados, 2012. p. 77- 92.

RÊGO, R. M.; RÊGO, R. G. Desenvolvimento e uso de materiais didáticos no ensino de matemática. In: LORENZATO, Sérgio. Laboratório de ensino de matemática na formação de professores. Campinas: Autores Associados, 2012. p. 39-56.

TURRIONI, A. M. S. O Laboratório de educação matemática na formação inicial de professores. Dissertação (Pós-graduação em Educação Matemática e seus fundamentos Filosóficos-Científicos) - Universidade Estadual Paulista, Rio Claro-SP. Orientador: Geraldo Perez. 2004, 168 p. 